\title{
Sivas ve Yöresinde Sığır Ayak Hastalıkları Prevalansının Belirlenmesi
}

\author{
İbrahim YURDAKUL", ilker ŞEN \\ Cumhuriyet Üniversitesi, Veteriner Fakültesi, Cerrahi Anabilim Dalı, Sivas, Türkiye.
}

Geliş Tarihi: 29.01.2018

Kabul Tarihi: 22.03.2018

Özet: Bu çalışmada; 2016-2017 yıllarında Sivas ve yöresinde sığırlarda görülen ayak hastalıkları prevalansının belirlenmesi amaçlandı. Çalışmanın materyalini Sivas ili ve merkeze bağlı köylerde bulunan değişik yaş, ırk ve cinsiyette toplam 1852 baş sığır oluşturdu. İncelenen olgularda 570 hayvanda sadece tırnak deformitesi, 74 vakada ayak hastalığı görülürken 74 olguda da tırnak deformitesi ile birlikte ayak hastalığı saptandı. Çalışmada tırnaklardaki deformasyonların dağılımı 154 olguda küt tırnak, 112 olguda sivri tırnak, 102 olguda tirbuşon tırnak, 108 olguda makas tırnak, 94 olguda yayvan-geniş-dolgun tırnak, 62 olguda ayrık tırnak ve 12 olguda ise gaga tırnak deformasyonu tespit edildi. Bu çalışmada ayak hastalığı belirlenen 148 adet sığırda toplam 170 adet lezyon belirlendi. Bu lezyonların 32 adedi ökçe çürüğü, 30 adedi tırnak çatlağı, 26 adedi taban ülseri, 18 adedi beyaz çizgi hastalığı, 12 adedi digital dermatit, 10 adedi interdigital dermatit, 10 adedi interdigital hyperplasia (limax), 10 adedi tırnak yarası, 6 adedi pododermatitis aseptica diffusa, 4 adedi pododermatitis aseptica circumscripta, 6 adedi yabancı cisim batması, 2 adedi ökçe apsesi, 2 adedi interdigital flegmon, 2 adedi corium ungulae de canlı doku üremesi oluşturdu. Sonuç olarak Sivas ve yöresinde sığırlarda ayak hastalıklarının yıllık prevalansı \%38.77 olarak tespit edildi.

Anahtar Kelimeler: Ayak hastalıkları, Prevalans, Sı̆̆ır.

\section{Investigation of Prevalance of Foot Diseases in the Cattle in the Region of Sivas}

Abstract: In this study; It was aimed to determine the prevalence of foot diseases seen in cattle in Sivas and its region in 2016-2017 years. The material of the study was 1852 head cattle in different age, race and gender in the villages of Sivas province and center. There were only digital deformities in 570 claws and only foot diseases in 74 claws. However, foot diseases with digital deformities were seen in 74 cattle. In this study, classification of the deformed claws as follows: Blunt claw in 154, Overgrown claw in 112, corkscrew claw in 102, scissor claw in 108 , splay claw in 94 , discrete claw in 62 , beak claw in 12. In this study, a total of 170 lesions were identified in 148 cattle with foot disease. These lesions can be detailed as; bruised sole in 32 , fissure ungulae in 30 , rusterholz ulcer in 26 , white line diseases in 18 , digitalis dermatitis in 12 , interdigital dermatitis in 10, interdigital hyperplasia (limax) in 10, ungulae wound in 10, pododermatitis aseptica diffusa in 6 , pododermatitis aseptica circumscripta in 4, foreign body invasion in 6 , heel abscess in 2, interdigital flegmon in 2, living tissue growth in corium ungulae in 2 . As a result, prevalence of foot diseases in cattle in and around Sivas were determined as $38.77 \%$

Keywords: Cattle, Foot disease, Prevalence.

\section{Giriş}

Günümüzde hayvancılık; gelişmiş ve gelişmekte olan ülkelerde ulusal ekonomiye katkı sağlayan önemli bir sektör konumundadır. Türkiye'de artan nüfus ve yükselen sosyo-ekonomik refaha bağlı olarak hayvansal ürünlere olan talebin giderek artması, üretim ve verimliliğin artırılmasını da gerekli kılmaktadır (Demir ve Aral, 2014). Süt ve besi sığırcılığında verimi artırmak amacıyla uygulanan kapalı ve yarı-kapalı sistem işletmeciliği gün geçtikçe yaygınlaşmaktadır (Şındak ve ark., 2003). Ancak kırsal kesimdeki işletmelerin halen önemli bir kısmını özellikle tarıma dayalı küçük işletmeler oluşturmaktadır. $\mathrm{Bu}$ tip işletmelerde bilgi yetersizliği, bakım ve beslenme şartlarının geleneksel ve kötü olması gibi sebeplerden dolayı istenilen verim elde edilememektedir (Demir ve Aral, 2014; Şındak ve ark., 2003). Modern süt sığır yetiştiriciliğinde ayak hastalıklarına bağlı ekonomik kayıplar; üreme performansının azalması, süt veriminin düşmesi, gebe kalma süresinin uzaması, hayvanların sürüden çıkarılması gibi durumları içermektedir (Huxley, 2013; Kamiloğlu ve Baran, 1999). Süt sığır yetiştiriciliğinde topallıkların \%90 sebebi olarak tırnak hastalıkları gösterilmektedir (Sogstad ve ark., 2005). Ayak hastalığı saptanan sığırlarda sağlıklı olan sığırlara oranla günlük süt verimi 1,12 kg ile 3,1 kg arasında azalmakta, gebe kalma süreleri 12 gün daha uzamakta ve \%1,17'si sürüden çıkarılmaktadır (Suleyaman ve Fromsa, 2012).

Ayak hastalıklarının etiyolojisinde laktasyon, canlı ağırlık, yaş, cinsiyet, gebelik ve genetik gibi bireysel faktörlerin yanı sıra kapalı veya yarı kapalı sistemlerde yetiştiricilik yapılan işletmelerde sığırların meraya çıkarılmaması, beton zeminlerde barındırma, altlık olarak gübre kullanılması, idrarın 
akışını sağlayacak \%3-4 lük eğimin bulunmaması ile dışkı kanallarının yeterli olmaması ve beslenme gibi işletmeye ait bir çok faktör ayak hastalıklarına sebep olmaktadır (Elma ve Kumandaş, 2015; Kamiloğlu, 2014; Mülling ve ark., 2006; Sogstad ve ark., 2005; Şındak ve ark., 2003; Yayla ve ark., 2012; Yaylak, 2008). Ayak hastalıklarının oluşumunda mevsimin topallık insidansı üzerine önemli bir etkisi vardır. Ayak hastalıkları en fazla yağışın bol olduğu MartNisan ve Kasım- Aralık aylarında artmaktadır. Ayrıca iklimin kurak olması da tırnaklarda da dehidrasyona, sertleşmeye, kırılganlığa ve çatlamaya yol açar (Mitey ve ark., 2012).

Bu çalışmada; Sivas ili ve civarındaki köylerde sığır ayak hastalıkları prevalansının ortaya konulması amaçlanmıştır.

\section{Materyal ve Metot}

Çalışmanın materyalini; 2016-2017 tarihleri arasında Sivas ili ve Sivas ili merkeze bağlı köylerde rastgele seçilen küçük, orta ve büyük ölçekli 70 adet işletmede bulunan değişik yaş, ırk ve cinsiyette toplam 1852 adet sığır oluşturdu. Çalışmayı oluşturan toplam 1852 baş sığırın 1302 adedi $(\% 70,30)$ dişi, 550 adedi $(\% 29,70)$ erkekti. Irklara göre hayvanların dağılımı ise; 910 adet $(\% 49,14)$ Montofon, 644 adet $(\% 34,77)$ Simental, 136 adet $(\% 7,34)$ yerli, 80 adet $(\% 4,32)$ melez, 66 adet $(\% 3,56)$ Holstein, 12 adedi $(\% 0,65)$ Şarole ve 4 adedi de $(\% 0,22)$ Belçika mavisinden oluştu. Ziyaret edilen işletmelerin fiziki yapısı, ahırların durumu, temizliği ve kapasitesi incelendi. Yetiştiricilerden hayvanların ırkı, yaşı, cinsiyeti, bakım ve beslenmesi ile ilgili alınan bilgiler kayıt edilerek hayvan sahiplerine ayak hastalıkları ve tırnak deformasyonlarının nedenleri ve bu nedenlere yönelik alınabilecek önlemler anlatıldı. Hasta sahibinden alınan anamnezden sonra topallık semptomu gösteren ayaklar yıkanıp temizlenerek lezyonun yerleştiği bölgeler belirlendi. Muayene sırasında tespit edilen deforme tırnakların kesilip düzeltilmesinde ve topallık gözlenen ayaklardaki lezyonun açığa çıkarılmasında tırnak kesme makası, sağ-sol renetler, tırnak törpüsü, elektrikli zımpara, tırnak muayene pensi ve operasyon seti kullanıldı.

İstatistiki analizler: Çalışmada elde edilen nonparametrik verilerin tanımlayıcı istatistikleri ile hastalık tipi, ırk ve cinsiyet gibi faktörlerle ilişkilerinin analizinde, SPSS 23.00 paket programı altında çalışan, Kruskal-Wallis, Ki-Kare ve MannWhitney-U testlerinden yararlanılmış; farklılıkların istatistiki anlamlılık düzeyi $p<0.05$ olarak alınmıştır.

\section{Bulgular}

Çalışmada incelenen işletmelerden özellikle küçük ahırların zeminlerinin daha çok toprak olduğu, altlık olarak gübre kullanıldığı, hijyenik şartlara uygun olmadığı ve plansız yapılar olduğu dikkati çekti. Küçük işletmelerdeki ahır ve barınakların çoğunda dışkı ve idrar kanallarının olmadığı, özellikle karlı ve yağışlı havalarda kar ve yağmur sularının dışkı ve idrar ile birlikte toprak zemininde oluşan çukurlarda yoğun bir şekilde birikmiş olduğu saptandı. Dışkı ve idrar kanalı olan ahırlarda ise hayvanın bulunduğu yer ile kanal arasındaki mesafenin kısa olmasından dolayı hayvanların arka ayaklarının bu kanallarda kaldığı belirlendi. Orta ve büyük ölçekli işletmelerde dışkı ve idrar kanallarının bulunmasına rağmen eğimlerinin düşük olması ve ahırların çoğunda bakıcı yetersizliğine bağlı olarak günde en az iki kez yapılması gereken zemin temizliğinin yapılamaması neticesinde dışkı ve idrarların beton zeminde birikmiş olduğu gözlemlendi. Sunulan bu araştırmada ayak hastalıkları yönünden ziyaret edilen işletmelerde gerek; ahırlarda yapılan tespitlerden gerekse; hayvan sahiplerinden alınan bilgilerden ayak ve tırnak bakımına yeterli derecede önemin verilmediği belirlendi. Hayvanların muayenesinde 1852 baş sığırın 570 tanesinde sadece tırnak deformasyonu, 74 adedinde tırnak deformasyonu ile birlikte lezyonlu ayak hastalığı, 74 adedinde ise sadece lezyonlu ayak hastalığı saptandı. Yapılan bu çalışmada toplam hayvanların 644 adedinde $(\% 34,77)$ tırnak deformasyonu (Tablo 1), 148 adedinde $(\% 7,99)$ lezyona bağlı ayak hastalığı belirlendi. Elde edilen bulgulara göre toplam 718 hayvanda tırnak deformiteleri ve lezyona bağlı ayak hastalıklarının görülme oranı \%38,77 olarak tespit edildi. (Şekil 1).

Tablo 1. Deforme tırnakların görülme oranları.

\begin{tabular}{lccc}
\hline $\begin{array}{l}\text { Deforme tırnak } \\
\text { yapıları }\end{array}$ & $\begin{array}{c}\text { Deforme } \\
\text { tırnak sayısı }\end{array}$ & $\%$ & $\mathbf{X}^{\mathbf{2}}$ \\
\hline Sivri tırnak & 112 & $17.39^{\mathrm{c}}$ & \\
$\begin{array}{l}\text { Tirbişon tırnak } \\
\text { Yayvan geniş }\end{array}$ & 102 & $18.84^{\mathrm{b}}$ & \\
dolgun tırnak & 94 & $14.60^{\mathrm{e}}$ & \\
Makas tırnak & 108 & $16.77^{\mathrm{d}}$ & 64 \\
Küt tırnak & 154 & $23.91^{\mathrm{a}}$ & $3^{*}$ \\
Ayrık tırnak & 62 & $9.63^{\mathrm{f}}$ & \\
Gaga tırnak & 12 & $1.86^{\mathrm{g}}$ & \\
Toplam & 644 & 100 & \\
\hline
\end{tabular}

*: $p<0.001$; aynı sütunda farklı harflerle gösterilen değerler arasındaki fark istatistiki olarak önemlidir $(p<0.01)$. 
Sunulan bu araştırmada ayak hastalığ belirlenen 148 adet sığırda toplam 170 adet lezyon belirlendi. Tespit edilen lezyonların 32 adedi $(\% 18,82)$ ökçe çürüğü, 30 adedi $(\% 17,65)$ tırnak çatlağı, 26 adedi $(\% 15,29)$ taban ülseri, 18 adedi $(\% 10,59)$ beyaz çizgi hastalığı, 12 adedi $(\% 7,06)$ digital dermatit, 10 adedi $(\% 5,88)$ interdigital dermatit, 10 adedi $(\% 5,88)$ limax, 10 adedi $(\% 5,88)$ tırnak yarası, 6 adedi $(\% 3,53)$ pododermatitis aseptica diffusa, 4 adedi $(\% 2,35)$ pododermatitis aseptica circumscripta, 6 adedi $(\% 3,53)$ yabanc cisim, 2 adedi $(\% 1,18)$ ökçe apsesi, 2 adedi $(\% 1,18)$ interdigital flegmon, 2 adedi $(\% 1,18)$ corium ungulae de canlı doku üremesi oluşturdu. Ayak hastalığı tespit edilen 148 adet hayvanda lezyonların ön ve arka ayaklarda görülme oranları ön ayaklarda $\% 21,84$ (ön sağ $\% 9,20$, ön sol $\% 12,64$ ), arka ayaklarda \%78,16 (arka sağ \%35,63, arka sol $\% 45,53)$ olarak belirlendi. Tırnak deformasyonları tespit edilen 644 adet hayvanda deformasyonların görülme oranları ise; ön ayaklarda \%54,39 (ön sağ
\%27, ön sol \%27,39), arka ayaklarda \%45,61 (arka sağ \%22,87, arka sol \%22,74) olarak tespit edildi.

Tablo 2. Irklara göre ayak hastalıklarının görülme oranları.

\begin{tabular}{lcccc}
\hline Hayvan Irkı & $\begin{array}{c}\text { Incelenen } \\
\text { Hayvan } \\
\text { Sayısı }\end{array}$ & $\begin{array}{c}\text { Hasta } \\
\text { Hayvan } \\
\text { Sayısı }\end{array}$ & $\%$ & $\mathbf{X}^{\mathbf{2}}$ \\
\hline Montofon & 910 & 270 & $29.67^{\mathrm{b}}$ & \\
Simental & 644 & 361 & $56.06^{\mathrm{a}}$ & \\
Yerli & 136 & 28 & $20.59^{\mathrm{c}}$ & \\
Holstein & 66 & 40 & $60.61^{\mathrm{a}}$ & 162. \\
Melez & 80 & 19 & $23.75^{\mathrm{c}}$ & $73^{*}$ \\
Sarole & 12 & - & - & \\
Belçika & 4 & - & - & \\
Mavisi & 1852 & 718 & 38.77 & \\
Toplam & & & & \\
\hline
\end{tabular}

: $p<0.001$; aynı sütunda farklı harflerle gösterilen değerler arasındaki fark istatistiki olarak önemlidir $(p<0.05)$.

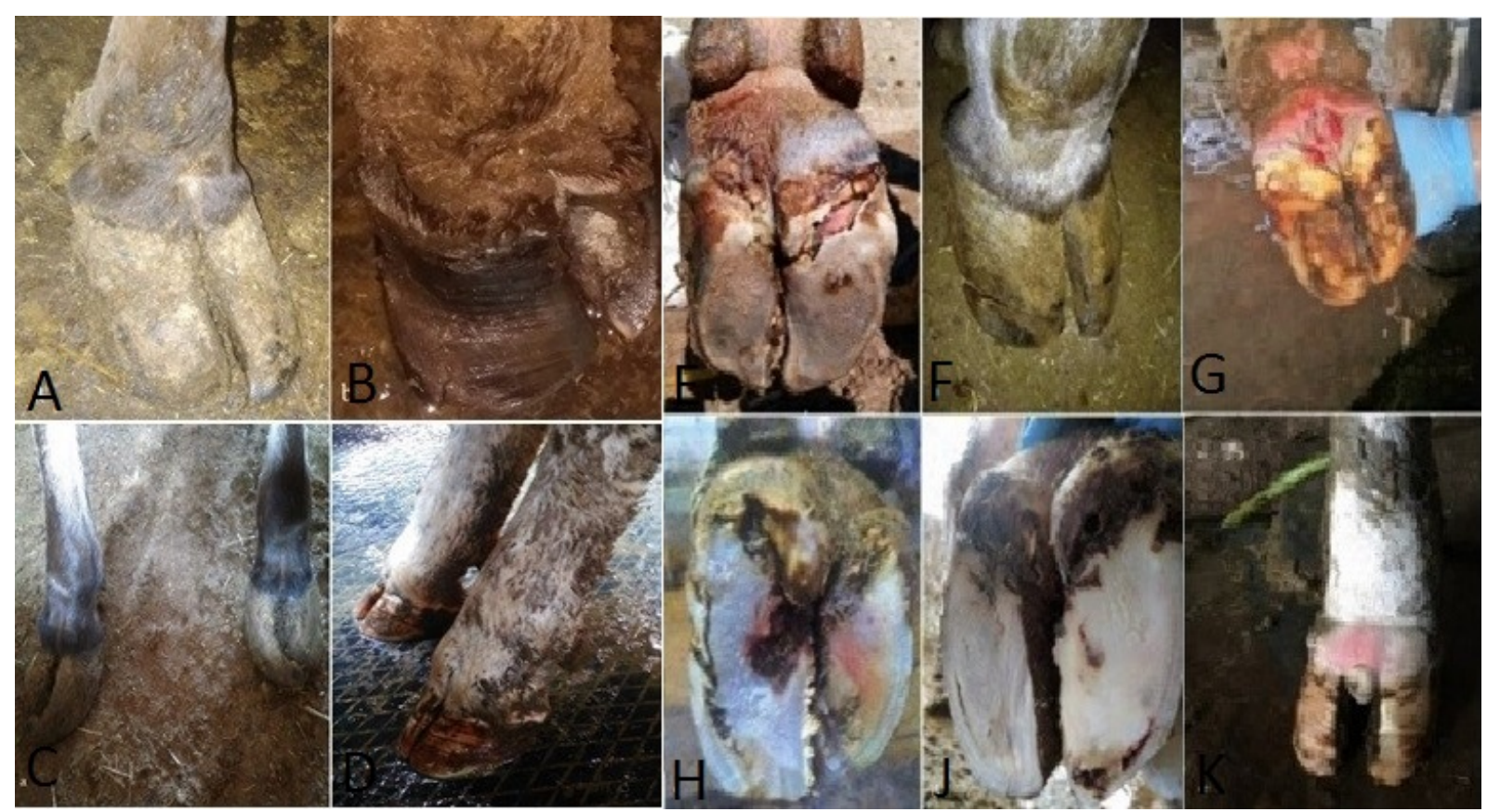

Şekil 1. Deforme tırnak yapıları ve ayak hastalıkları, A: Sivri tırnak, B: Tirbişon tırnak, C: Makas tırnak, D: Küt tırnak, E: Ökçe çürüğü, F: Tırnak çatlağı, G: Digital dermatit, H: Taban ülseri, J: Beyaz çizgi hastalığı, K: Limax.

\section{Tartışma ve Sonuç}

Ayak hastalıklarının modern süt sığır yetiştiriciliğinde büyük ekonomik kayıplara yol açtığı, ciddi sağlık sorunlarına neden olduğu, süt sığırcılığı problemleri arasında infertilite ve mastitisten sonra üçüncü sırada yer aldığı bilinmektedir (Hoffman ve ark., 2012; Mohsina ve ark., 2014; Salcı, 2015; Suleyaman ve Fromsa, 2012).
Yapılan araştırmalarda süt sığırlarında görülen ayak hastalıkları insidansının \%1-25 arasında değiştiği, bazı kaynaklarda ise bu oranın \%30 ve üzerinde olduğu belirtilmektedir (Atasoy, 2003). Sunulan bu çalışmada; Sivas ve yöresindeki sığırlarda tespit edilen ayak hastalıklarının görülme oranı \%38,77 olarak saptanmıştır. Atasoy (2003); Erzurum ve yöresinde yaptığı çalışmada \%82,79 oranında tırnak deformasyonu, \%22,72 oranında ayak hastalığı 
tespit etmiş ve tırnak deformitelerinin yüksek görülme nedenini ise iklim şartlarına ve çalışmanın kış aylarında yapılmasına bağlamıştır. Şındak ve ark. (2003) Şanlıurfa ve yöresinde yaptıkları çalışmada kapalı sistem işletmelerinde ayak hastalığının görülme oranını \%93,8 olarak belirtmişler ve bunu kapalı sistem işletmelerinde ayak bakımının yapılmamasına bağlamışlardır. Han ve ark. (2017) Muş ve yöresinde sığırlarda ahır zemin tiplerinin ayak hastalıkları ve tırnak deformasyonları üzerine etkileri hakkında yaptıkları çalışmada ayak hastalıkları ve tırnak deformitelerini beton zeminli barınaklarda \%32,97, toprak zeminli barınaklarda $\% 46,28$, taş zeminli barınaklarda \%8,51, tahta zeminli barınaklarda \%5,57 ve kauçuk zeminli barınaklarda \%6,66 olarak bildirmektedirler. Yaptığımız bu çalışmada orta ve büyük ölçekli işletmelerde ahır zeminlerinin beton, küçük işletmelerde ise toprak olması, ahır zeminlerinde yeterince hijyen kurallarına dikkat edilmemesi, ayrıca çalışmaların yapıldığı bölgelerin iklim koşullarının birbirlerine benzerlik göstermesi yönünden Atasoy (2003) ve Han ve ark. (2017)'nın, ayak bakımının yapılmaması yönünden ise Şındak ve ark. (2003)'nın yaptıkları çalışma sonuçlarını destekler niteliktedir.

Simental, Montofon ve Holstein gibi kültür ırkı sığır yetiştiriciliğinin ülkemizde yaygınlaşması ile ayak hastalıklarının arttığı çeşitli araştırmacılar tarafından (Atasoy, 2003; İstek ve Durgun, 2004; Keskin ve Durmuş, 2016; Ormancl ve Belge, 2001; Yayla ve ark., 2012) bildirilmektedir. Yapılan bu çalışmada ayak hastalıklarının ırklara göre dağılımında; Holstein ırkı \%60.61, Simental ırkı \%56.06, Montofon ırkı \%29.67, Melez ırk \%23.75 ve Yerli ırk sığırlarda \%20,59 olarak saptandı. Bu araştırmada hasta hayvanların ırklara göre dağılımı incelendiğinde en yüksek oranın Holstein ve Simental ırkı hayvanlarda olduğu görülmektedir (Tablo 2). Ayak hastalıklarının cinsiyete göre dağılımlarında Alkan ve ark. (1993) hasta sığırların \%86,36'sını dişi, \%13,64'ünü erkek, Canpolat ve Bulut (2003) \%82'sini dişi, \%18'ini erkek, İstek ve Durgun (2004) \%79,31'ini dişi, \%20,69'unu erkek, Yayla ve ark. (2012) \%51.80'nini dişi, \%48,2'sini erkek hayvanlar olarak bildirmişlerdir. Bu çalışmada ayak hastalığı belirlenen sığırların cinsiyete göre dağılımları; dişilerde \%71,62, erkeklerde \%28,38 olarak tespit edilerek dişi sığırlarda ayak hastalıkları görülme oranı erkeklere göre daha yüksek saptandı. Bazı araştırmacılar (Canpolat ve Bulut, 2003; i̇stek ve Durgun, 2004; Ormancı ve Belge, 2001; Özcan ve Pamuk, 2009); deforme tırnak yapılarının ayak hastalıkları oluşumunda önemli bir etken olduğunu ve ülkemizde tırnak deformasyonlarının \%25'in üzerinde seyrettiğini bildirmektedirler. Bu çalışmada 1852 adet sığırın 570 adedinde (\%30.78) sadece tırnak deformasyonu, 74 adedinde (\%4) tırnak deformasyonu ile birlikte ayak hastalığı, 74 adedinde (\%4) ise sadece ayak hastalığı saptandı. Tırnak deformitelerinin görülme nedeni olarak iklim şartları, ahır zemin tiplerinin yapısı, ahır zemininde altık kullanımaması, hayvanların yeterince gezdirilmemesi ve gerekli tırnak bakımı yapılmaması sonucu şekillendiği kanısına varıldı.

Ayak hastalıkları üzerine yapılan çalışmalarda bazı araştırmacılar (Canpolat ve Bulut, 2003; İstek ve Durgun, 2004; Keskin ve Durmuş, 2016); en fazla tırnak bozukluğunun sivri tırnak, makas tırnak, burulmuş tırnak, yayvan, geniş ve dolgun tırnak olarak belirtmişlerdir. Sunulan bu çalışmada da 154 olguda $(\% 23,91)$ küt tırnak, 112 olguda $(\% 17,39)$ sivri tırnak, 102 olguda $(\% 15,84)$ tirbuşon tırnak, 108 olguda $(\% 16,77)$ makas tırnak, 94 olguda $(\% 14,60)$ yayvan-geniş-dolgun tırnak, 62 olguda $(\% 9,63)$ ayrık tırnak ve 12 olguda $(\% 1,86)$ ise gaga tırnak olmak üzere toplam 644 adet tırnak deformasyonu tespit edilmiştir. Ayak hastalıklarına sebep olan lezyonların ön ayaklara oranla arka ayaklarda daha fazla yerleştiği bildirilmektedir (Canpolat ve Bulut, 2003; İstek ve Durgun, 2004; Yayla ve ark., 2012). Araştırmada ayak hastalıklarının \%21.84'ünün ön, \%78.16'sının arka ayaklarda şekillendiği saptandı. Ayak hastalıklarının arka ayaklarda \%78.16 gibi yüksek oranda görülmesinin nedeni; gerekli tırnak bakımının yapılmaması, vücut ağırlığı, gebelik, laktasyon ve memenin büyük olması gibi faktörlere bağlı olarak vücut ağırlığının arka ayaklar üzerine fazla yük binmesi olarak düşünülmektedir.

Çeşitli araştırmacılar (Atasoy, 2003; İstek ve Durgun, 2004; Yayla ve ark., 2012) tarafından ayak hastalıkları üzerine yapılan çalışmalarda interdigital dermatitis, digital dermatit, interdigital hiperplazi, beyaz çizgi hastalığı, ökçe apsesi, ökçe eziği, tırnak yarası, tırnak çatlağı, pododermatitis aseptica diffusa, pododermatitis septica, pododermatitis circumscripta gibi hastalıkların yaygın olarak görüldüğü belirtilmektedir. Bu çalışmada tespit edilen lezyonların 32 adedini $(\% 18,82)$ ökçe çürüğü, 30 adedini tırnak çatlağı $(\% 17,65), 26$ adedini $(\% 15,29)$ taban ülseri, 18 adedini $(\% 10,59)$ beyaz çizgi hastalığı, 12 adedini $(\% 7,06)$ digital dermatit, 10 adedini $(\% 5,88)$ interdigital dermatit, 10 adedini $(\% 5,88)$ interdigital hiperplazi, 10 adedini $(\% 5,88)$ tırnak yarası, 6 adedini $(\% 3,53)$ pododermatitis aseptica diffusa (laminitis, arpalama), 4 adedini (\%2,35) pododermatitis aseptica circumscripta, 6 adedini $(\% 1,76)$ yabancı cisim, 2 adedini $(\% 0,59)$ ökçe apsesi, 2 adedini $(\% 0,59)$ interdigital flegmon, 2 adedini $(\% 0,59)$ corium ungulaede canlı doku 
üremesi oluşturdu. Elde edilen bu veriler doğrultusunda yukarıda ismi geçen ayak hastalıklarının yaygın olarak görülmesi Atasoy (2003)'un Erzurum bölgesinde, Canpolat ve Bulut (2003)'un Elazığ bölgesinde, İstek ve Durgun (2004)'un Muş bölgesinde, Keskin ve Durmuş (2016)'un Gaziantep bölgesinde, Yayla ve ark. (2012)'nın Kars bölgesinde yaptıkları çalışmaya paralellik göstermektedir. Çalışmada elde edilen veriler ve yapılan incelemeler doğrultusunda Sivas ili ve çevresinde süt sığır yetiştiricilerinin barınak hijyen şartlarına, tırnak bakımına ve topallıklara gereken önemi vermedikleri tespit edilmiştir.

Sonuç olarak; bölge hayvancılığında önemli ekonomik kayıplara neden olan ayak hastalıklarının önüne geçilebilmesi ve istenilen verimin elde edilebilmesi için yetiştiricilerin bilinçlendirilerek sığırlarda gebelik süresinin uzaması, süt verimi düşüklüğü, kısırlık, besi performansı, sürüden ayıklama gibi ekonomik kayıpların önüne geçileceği kanısına varılmıştır.

\section{Kaynaklar}

Alkan i, Boynukara B, Gençcelep M, 1993: Van ve yöresinde sığır ayak hastalıklarının yayılışı, nedenleri ve sağaltımı üzerine bir araştırma. YYÜ. Vet. Fak. Derg.4(1-2): 87-95.

Atasoy N, 2003: Erzurum yöresinde süt sığırlarında görülen ayak hastalıklarının insidansı ve bunların sağaltımı. YYÜ. Vet. Fak. Derg, 14, 1, 1-5.

Canpolat I, Bulut S, 2003: Elazığ ve çevresinde sığırlarda görülen ayak hastalıklarının insidansı üzerine gözlemler. F.Ü. Sağlık Bil. Dergisi, 17, 3, 155-60.

Demir P, Aral Y, Sarı̈zkan S, 2014: Kars ili süt sığırcllık işletmelerinin sosyo-ekonomik yapısı ve üretim maliyetleri. YYÜ. Vet. Fak. Derg. 25, 1, 1-6.

Elma E, Kumandaş A, 2015: Sığırlarda tırnak kesimi. Türkiye Klinikleri J Vet Sci Surg-Special Topics, 1, 1, 73-77.

Han MC, Sağlıyan A, Polat E, 2017: Sığırlarda ahır zemin tiplerinin ayak hastalıkları ve tırnak deformasyonları üzerine etkilerinin araştırılması. Harran Üniv. Vet. Fak. Dergisi, 6, 1, 19-24.

Hoffman AC, Moore DA, Vanegas J, Wenz JR, 2012: Rationale for a dairy herd lameness investigation strategy. Ag Animal Health Spotlight Veterinary Medicine Extension. Washington State University, 19.

Huxley JN, 2013: Impact of lameness and claw lesions in cows on health and production. Livestock Sci. 156, 13, 64-70.

İstek Ö, Durgun T, 2004: Muş ve yöresindeki sığırlarda görülen ayak hastalıklarının prevalansı üzerine araştırmalar. Doğu Anadolu Bölgesi Araştırmaları, 39-47.
Kamiloğlu A, 2014: Çiftlik Hayvanlarında Ayak Hastalıkları. 1. Baskı., Medipres, Ankara, Türkiye.

Kamiloğlu A, Baran B, 1999: Kars yöresinde simental ırkı sığırlarda interdigital deri lezyonlarının insidansı ve bunların intravenöz regional antibiyoterapi (ivregab) ile sağaltımı. Kafkas Üniv Vet Fak Derg, 5, 1, 93-102.

Keskin E, Durmuş AS, 2016: Gaziantep ve yöresinde gözlenen sığır ayak hastalıklarının insidansı ve tedavileri üzerine gözlemler. F. Ü. Sağ. Bil. Vet. Derg, 30, 3, 181-186.

Mitev J, Penev T, Vasilev N, Miteva TCH, Gergovska ZH, Uzunova KR, 2012: Effect of lameness on some productive traits and health status of cows in dairy cattle farms. Trakia J.Sci, 10, 1, 85-91.

Mohsina A, Zama MMS, Tamilmahan P, Gugjoo MB, Singh K, Gopinathan A, Gopi M, Karthik K, 2014: A retrospective study on incidence of lameness in domestic animals. Veterinary World, 7, 8, 601-604.

Mülling CKW, Green L, Barker Z, Scaife J, Amory J, Speijers $M, 2006$ : Risk factors associated with foot lameness in dairy cattle and a suggested approach for lameness reduction. XXIV. World Buiatrics Congress, Nice, France.

Ormancı S, Belge A, 2001: Van ve yöresinde süt sığırlarında ayak hastalıklarının nedenleri, dağılımı ve sağaltımı üzerine çalışmalar. YYü. Sağ. Bil. Derg. 7, 1-2, 139-145.

Özcan S, Pamuk K, 2009: Afyonkarahisar ve çevresinde sığır ayak hastalıklarının prevalansı. Kocatepe Vet J, 2, 2, 15-19.

Salcı H, 2015: Sığırlarda Ayak hastalıklarının radyolojik ve biyomekanik ilişkilendirilmesi: 13 olguluk bir ön çalışma, Uludağ Üniv. J. Fac. Vet. Med, 34, 1-2, 8993.

Sogstad AM, Fjeldaas T, Qsteras O, 2005: Lameness and claw lesions of the norwegian red dairy cattle housed in free stals in relation to environment, parity and stage of lactation. Acta Vet. Scand, 46, 203-217.

Suleyaman M, Fromsa A, 2012: Lameness in dairy cattle: prevalence, risk factors and Impact on milk production. GV, 8, 1, 1-7.

Şındak N, Keskin O, Selçukbiricik H, Sertkaya H, 2003: Şanlıurfa ve yöresinde sığır ayak hastalıklarının prevalansı. YYÜ. Vet. Fak. Derg, 14, 1, 14-18.

Yayla S, Aksoy Ö, Kılıç E, Cihan M, Özaydın I, Ermutlu CŞ, 2012: Kars ve yöresinde sığırların bakım ve barındırma koşulları ile ayak hastalıkları arasındaki ilişkinin değerlendirilmesi. Harran Üniv. Vet. Fak. Dergisi. 1, 1, 22-27.

Yaylak E, 2008: Süt sığırlarında topallık ve topallığın bazı özellikleri. Hay. Üretim, 49, 47-56

** : Bu çalışma Cumhuriyet Üniversitesi Bilimsel Araştırma Projeleri Birimi tarafından (CÜBAP V-045) desteklenmiştir.

${ }^{*}$ Yazışma adresi: İbrahim YURDAKUL

Cumhuriyet Üniversitesi Veteriner Fakültesi, Cerrahi Anabilim Dalı, Sivas, Türkiye.

e-mail: ibrahimyurdakul5858@hotmail.com 